\title{
Exploring Porphyry Copper Deposits in the Central Iran Using Remote Sensing Techniques
}

\author{
Akram Mahan*, Ramin Arfania \\ Isfahan (Khorasgan) Branch, Islamic Azad University, Isfahan, Iran \\ Email: *Akram.mahan@hotmail.com
}

How to cite this paper: Mahan, A. and Arfania, R. (2018) Exploring Porphyry Copper Deposits in the Central Iran Using Remote Sensing Techniques. Open Journal of Geology, 8, 606-622. https://doi.org/10.4236/ojg.2018.86035

Received: May 23, 2018

Accepted: June 16, 2018

Published: June 21, 2018

Copyright ( $) 2018$ by authors and Scientific Research Publishing Inc. This work is licensed under the Creative Commons Attribution International License (CC BY 4.0).

http://creativecommons.org/licenses/by/4.0/

(c) (i) Open Access

\begin{abstract}
This study used the ability of remote sensing technology to identify alteration zones in porphyry copper mining and Iron oxides of area in south Nain district in Iran by using Lands at- 8 data source. The band ratio of $3 / 2$ derived from image spectra was used to indicate the distribution of iron oxides and $6 / 3$ for identifying gossan. Hydrothermal alteration mineral zones associated with porphyry copper mineralization identified and discriminated based on two algorithms of target detection, MTTCIMF and OSP. Those techniques identified porphyry copper mineralization in study area and six points were diagnosed as the best location for ore exploration. For more accurate study and recognition between mineralization and tectonic structure of district, the lineament map of area was produced by applying Gaussian high-pass filter on IRS data. The Spatial distribution of hydrothermal alteration zones has been verified by inspection in field works and Fuzzy logic. Results showed that image processing techniques have a great ability to obtain comprehensive information for reconnaissance stage of porphyry copper exploration in the case study and assist researcher to explore porphyry copper and iron oxides regions before time-consuming and costly ground investigation.
\end{abstract}

\section{Keywords}

Fuzzy Logic, OSP, MTTCIMF, Lands at-8, Gossan, Porphyry Copper Exploration

\section{Introduction}

Satellite Remote sensing is a useful tool for mapping lithology and surface mineralogy and exploring ore deposits [1] [2] [3] [4]. Multispectral remote sensing datasets which capture data in wide ranges of electromagnetic spectrum help researcher to identify minerals. Each mineral has specific chemical composition 
and crystal structure with specific absorption and reflection range in electromagnetic spectrum. Hydrothermal fluids processes that alter the mineralogy and chemical composition of rock generate porphyry ore deposits. Early studies of alteration mineral assemblages emphasized zonal arrangements of mineralogy around several porphyry copper deposits. Each zone depending on different minerals assemblages has diagnostic spectral absorption features in visible, NIR and SWIR regions of Lands at-8 data [5] [6] [7]. Series of recognized alteration zones are: Potassic, Argillic, Phyllic and propylitic. A core of quartz and other forms of silica (chalcedony, opal, amorphous silica) with potassium-bearing minerals are surrounded by multiple zones. Other zones contain clay such as illite, sericite, smectite, chlorite and other hydroxyl minerals with diagnostic spectral absorption properties in the Visible, SWIR, NIR spectrum. The first clue for exploring ore deposits is studying the behavior of minerals assemblages of each alteration zone in. The second clue is Supergene alteration processes over porphyry copper bodies produce rust-colored and oxide and hydroxide minerals of iron and manganese which are termed Gossan [1] [8]. Gossan forms by the oxidation of the sulfide minerals in an ore deposit and they thus may be used as clues to the existence of subsurface ore deposit. The spectroscopy of minerals assemblage of each altered zone indicate that muscovite (sericite) show an intense $\mathrm{Al}-\mathrm{OH}$ absorption feature centered at $2.20 \mu \mathrm{m}$ and a less intense absorption feature at $2.35 \mu \mathrm{m}$ that characterized as phyllic zone. The argillic zone is characterized by Kaolinite and alunite that have absorption features situated in the $2.165 \mu \mathrm{m}$ and $2.2 \mu \mathrm{m}$. The propylitic zone including epidote, chlorite and calcite have absorption features at $\mathrm{Fe}, \mathrm{Mg}-\mathrm{OH}$ and $\mathrm{CO}_{3}$ in the $2.31 \mu \mathrm{m} 2.33 \mu \mathrm{m}$ Figure 1(a) shows the spectral library of minerals [2] [5] [9]-[15]. Iron oxide and hydroxide minerals such as limonite, jarosite and hematite tend to have

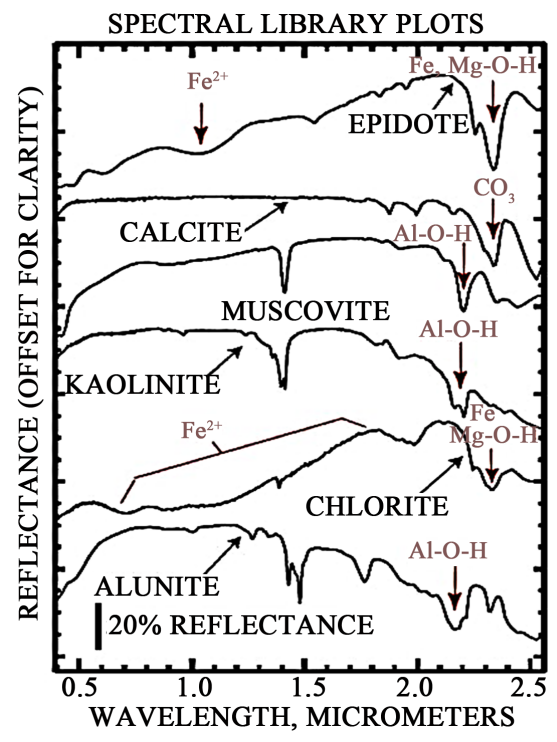

(a)

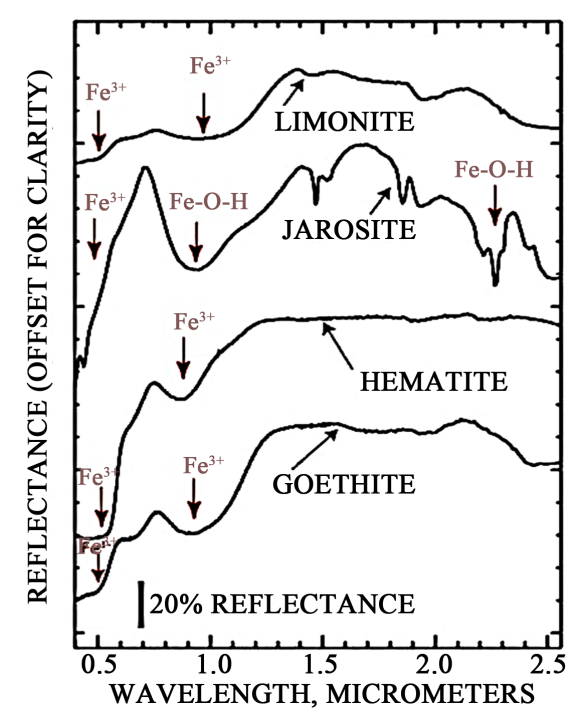

(b)

Figure 1. (a) Laboratory spectra of epidote, calcite, muscovite, kaolinite, chlorite and alunite; (b) laboratory spectra of limonite, jarosite, hematite and goethite (Clark et al., 1993). 
spectral absorption features in the visible to middle infrared from 0.4 to $1.1 \mu \mathrm{m}$ of the electromagnetic spectrum shows in Figure 1(b). The purpose of this paper is to utilize Lands at- 8 data for mapping hydrothermal alteration mineral zones associated with porphyry copper mineralization and detect gossan and Iron oxides.

\section{Materials and Methods}

\subsection{Geological Setting}

Iran is a semi-arid country. It has been divided into several units depends on a relatively unique record of stratigraphy, magmatic activities, metamorphism orogenic event, tectonics and overall geological style [17]. The ore deposit of Iran were developed in the middle part of Tethyan orogenic and metallogenic belt. The study of area is located in the west of central Iran unit on Urumiyeh-Dokhtar Volcanic belt (U-DVB). This belt is the largest volcanic belt in central Iran. The belt by NW-SE trending is the most important volcano-plutonic complex with economic potential for copper mineralization. Subduction of the Arabian plate beneath central Iran during Alpine-Himalayan orogenic formed Urumiyeh-Dokhtar volcanic belt. This study focuss on south of Naein city at $\left(55^{\circ} 45^{\prime} \mathrm{E}-55^{\circ} 45^{\prime} \mathrm{E}\right.$ and $\left.32^{\circ} 15^{\prime} \mathrm{N}-32^{\circ} 25^{\prime} \mathrm{N}\right)$ Figure 2 shows the location of area. Rock units of area consist of three parts: 1) Paleozoic sedimentary rocks consist of dolomite and carbonate rocks. 2) Igneous rocks and volcanic-sedimentary rocks belong to cretaceous and clastic rocks and volcanic rocks belong to Oligocene. 3) Ophiolite complex inclusion serpentinite, peridotite, with harzburgite, diabase dike with low and medium grade metamorphism, rodingite dike, listvenite rocks and radiolarian cherts belongs to upper cretaceous Figure 3 [16].

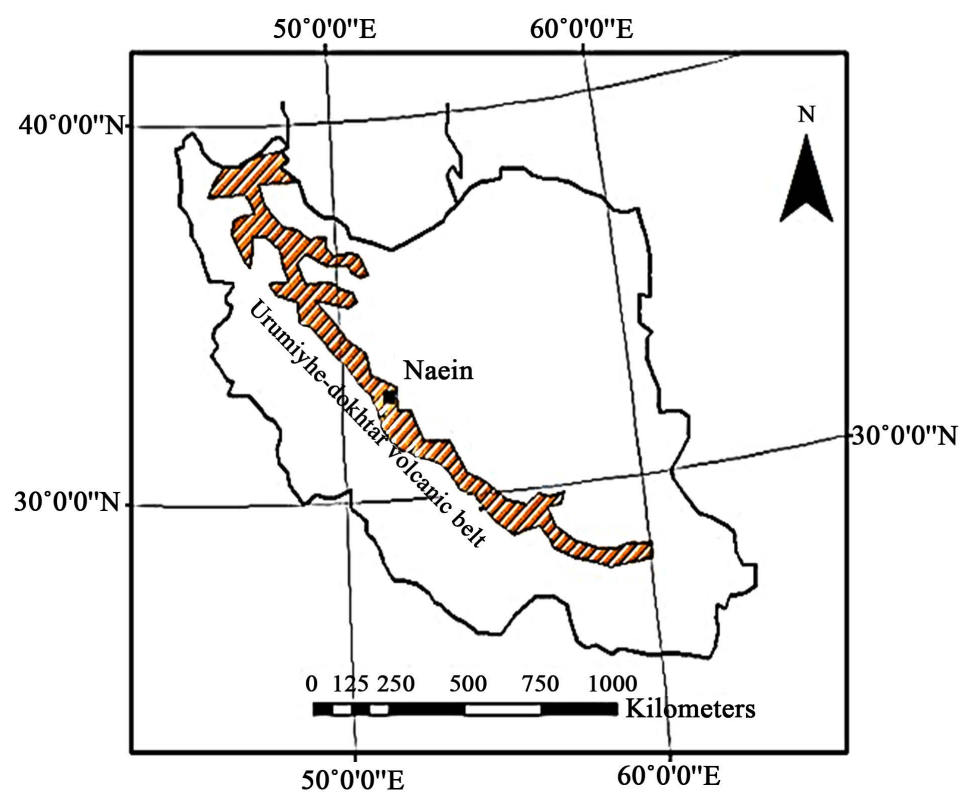

Figure 2. Location of Naein and Urumiyhe-dokhtar volcanic belt in Iran. 

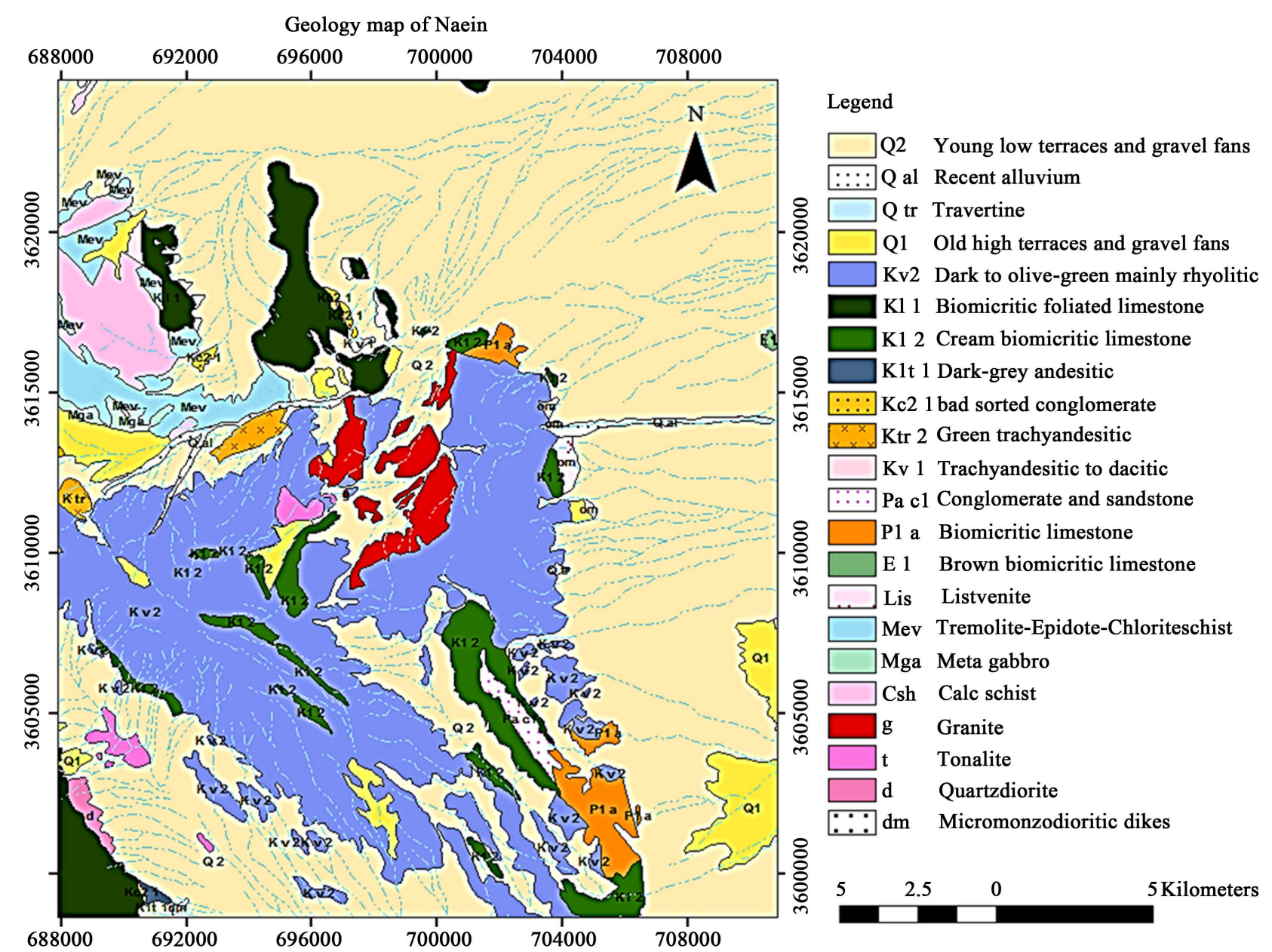

Figure 3. Geology map of study, Naein (GSI, 2004).

Two main faults, Dehsheer-Baft from East and Qum-Zefreh from west have confined the district. The function of them produced transvers faults in area. Qum-Zefreh fault system reflects a dextral strike-slip displacement that have had an important role in generating igneous rocks in area. Deh-sheer fault is lateral strike-slip and colored melange complex can be seen in length of it in Naein area... Being ensnared between two faults allows lava to stay and alter the surrounding rocks. The result of this operation is alteration of dacite rocks which have lost their chemical structure and have changed to chlorite and Sericite. During this process minerals such as magnetite, Chalcopyrite, Chalcocite, Bornite were formed (GIS, 2004). The altered rocks in this area confirm the presence of porphyry copper deposit.

\subsection{Remote Sensing Data}

\subsubsection{Lands at 8 (OLI)}

Lands at 8 is a North American Earth observation satellite launched on February 11, 2013. Lands at8 data can be downloaded at (http://earthexplorer.usgs.gov) and has been used in wide range of studies [18] [19] [20]. 
Lands at 8 carries two instruments: The Operational Land Imager $(\mathrm{OLI})^{1}$ sensor and Thermal Infrared Sensor (TIRS) ${ }^{2}$ This satellite image has 11 bands: 5 in the visible and Near-infrared (VNIR), 2 in the thermal infrared (TIR) region of the electromagnetic spectrum, 2 in the SWIR region, new band (ultrablue) for coastal and aerosol studies and another new band for cirrus cloud detection and 1 panchromatic channel (band 8). Spatial resolution is 15 meters for the panchromatic band, 30 meters for VNIR and SWIR bands and 100 meters for the TIR bands. The images which has been used in this study was downloaded from US Geological Survey (USGS) website on July 25, 2013 consisted of cloud free level 1 Terrain corrected (L1T) scene of the study area in central Iran. The level $1 \mathrm{~T}$ data product provides systematic radiometric accuracy, geometric accuracy by incorporating ground control points, while also employing a digital elevation model DEM for topographic accuracy (https://landsat.usgs.gov/landsat-8-18-data-users-handbook-section-4).

The images were pre-georeferenced to UTM zone 39 North projection with using the WGS-84datum. In addition Lands at8 L1T data converted to reflectance using the Internal Average Relative Reflection IAAR method. This dialog is used to convert raw DN values to relative reflectance and that is more useful for mineralogical mapping for this study. This algorithm is recommended for mineralogical mapping as a preferred calibration technique, which it dose not necessitate to have the prior knowledge of samples that collected from the field. This is particularly effective for reducing hyperspectral data to relative reflectance in an area where no ground measurements exist and little is known about the scene. For this case study just bands of OLI sensor consist of 2, 3, 4 in visible region, 5 in near infrared and 6, 7 that are posited in SWIR region, were processed and analyzed by ENVI (Environment For Visualizing Image) version 5.1.

\subsubsection{IRS Data}

The Indian remote sensing satellite (IRS) ${ }^{3}$ was launched on December 17, 1988. In this study IRS satellite data obtained from geological survey of Iran on may20, 2015. In this case study just panchromatic band of IRS data were utilized because of its high spatial resolution. The image converted to universal Transverse Mercator zone $39 \mathrm{~N}$ from the WGS-84 datum. Figure 4 shows the Flow chart of research methodology in this study.

\subsection{Band Ratio}

Band ratio Images improve the contrast between features by dividing Digital number value of one band to the Digital number value of another band. Band ratios are very useful for highlighting certain feature or minerals that cannot be seen in the raw bands [21]. Band ratio transformation is useful for qualitative detection of hydrothermal alteration minerals, lithological units and lineaments of area [1] [22] [23] [24].

${ }^{1}$ Operational Land Imager.

${ }^{2}$ Thermal InfraRed Sensor.

${ }^{3}$ Indian Remote Sensing. 


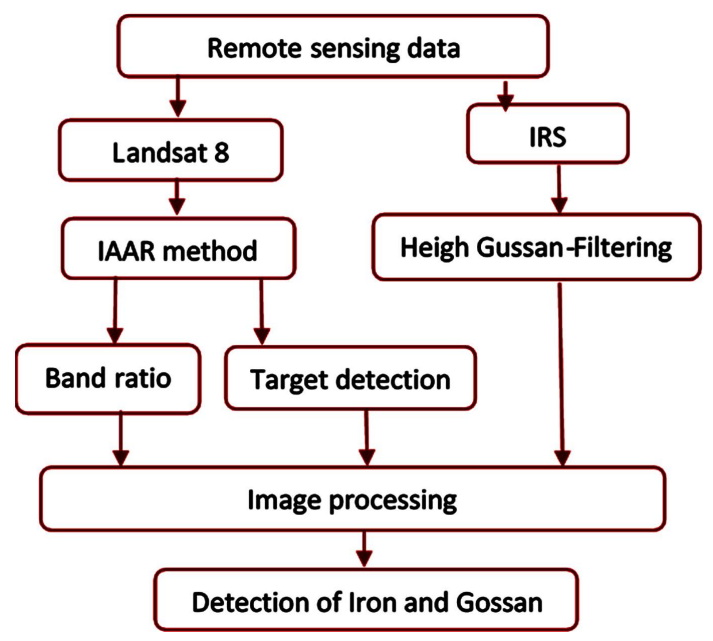

Figure 4. Flow chart of area.

\subsection{Target Detection}

This study describes the utility of Lands at-8 OLI data for sub-pixel mineral investigation using target detection algorithms for identification hydrothermal alteration zones. Satellites acquire images of earth surface in many electromagnetic spectrums in such a way that a complete spectral pattern of each pixel can be derived for target detection, discrimination and classification. Most of the surface minerals show diagnostic spectral signature in VNIR and SWIR of electromagnetic spectrum which enables their detection base on characteristics spectral signature. Minerals detected according to the similarity of the Image pixel with the reference spectra based on the threshold value derived from standard spectrum database [9] [11] [25]. In previous studies application of algorithms such as Matched Filtering (MF) and $\mathrm{MTMF}^{4}$ for sub-pixel target detection were investigated [26] [27] [28]. However, still these algorithms are not effective in minimizing the effect of interferences on the spectral mapping. In this study MTTCIMF $^{5}$ algorithm developed by Jin et al., 2009 and OSP algorithm were implemented for sub-pixel mineral investigation to detect target minerals correctly.

1) OSP

Orthogonal Subspace Projection (OSP $)^{6}$ first designs to eliminate the response of non-targets, then applies matched filter (MF) to match the desired target from the data. The matched filter is the optimal linear filter for maximizing the signal to noise ratio (SNR) in the presence of additive stochastic noise [29]. OSP idea is based on two aspects: 1) how to best utilize the target knowledge provided a priori and 2) how to effectively make use of available contiguous spectral bands [30]. OSP is efficient and effective when target signatures are distinct. When the spectral angle between the target signature and the non-target signature is small, the attenuation of the target signal is dramatic and the performance of OSP

${ }^{4}$ Mixture Tuned Matched Filtering.

${ }^{5}$ Mixture Tuned Target-Constrained Interference-Minimized Filter.

${ }^{6}$ Orthogonal Subspace Projection. 
could be poor. This method is only available if you provided more than one target spectra [31].

\section{2) MTTCIMF}

MTTCIMF developed by [32] which was implemented on processed Hyperion data for subpixel mineral investigation. The algorithm combines MTMF and $\mathrm{TCIMF}^{7}$ target detectors which offers opportunity to provide target as well as non-target information for improved sub-pixel target detection [33]. MTMF uses MNF transformed bands to perform MF and it add an infeasibility Image to reduce the number of false positives. TCIMF is constrained to eliminate the response of non-targets and minimization of interfering effects to improve the efficiency of spectral mapping [34].

\subsection{Filtering}

Lineaments are natural and man-made geomorphic features that have a surface expression, which could be fault, fracture, dykes, geological sharp boundaries or artificial road and canals Gaussian high-pass filter used to enhance the lineaments from IRS satellite image. The experience has shown that the best interpretation is achieved with the use of the panchromatic band, which has high spatial resolution $(5 \mathrm{~m}$ ) that will increase the accuracy and precision of detecting lineaments. In order to obtain a better image for interpretation, processing with Gaussian high-pass filtering technique take place. The function of this technique is to enhance the high frequency components. The linear and edge in the original image become more obvious and sharper in the filtered image. The aim of detecting lineaments in this research is to clear relationship between lineament and mineralization in the case study. Lineaments have important role in initial mineral exploration. Mineralization is associated with Lineaments, vein and shear zone systems when those are active. The aim of detecting lineaments of this study is to clear relationship between lineaments of study area with porphyry copper mineralization that will be find through image processing. The relationship between lineaments, structure, and mineralization was emphasized by [35]. Figure 5 shows lineaments of area.

\section{Results and Discussion}

Lands at -8 consisted of 11 bands. The first spectral band of $(0.433-0.453 \mu \mathrm{m})$ is a deep-blue band designed for studies of coastal water and aerosols and cannot be used to detect geological features. So it was therefore excluded from research. Band 2 is positioned in the blue $(0.450-0.515 \mu \mathrm{m})$, band 3 in the green $(0.525$ $0.600 \mu \mathrm{m})$ and band 4 in the red $(0.630-0.680 \mu \mathrm{m})$. Band 5 is located in $(0.845-$ $0.88 \mu \mathrm{m})$ near-infrared region of electromagnetic spectrum. Short wave infrared (band 6: $1.560-1.660 \mu \mathrm{m}$, band 7: $2.100-2.300 \mu \mathrm{m}$ ) is used for imaging soil types, geological features and minerals such as copper and sulfates. Panchromatic, cirrus cloud (band 9) and TIR bands (band 10: $10.6-11.1 \mu \mathrm{m}$, band 11:

${ }^{7}$ Target-Constrained interference-minimized filter. 


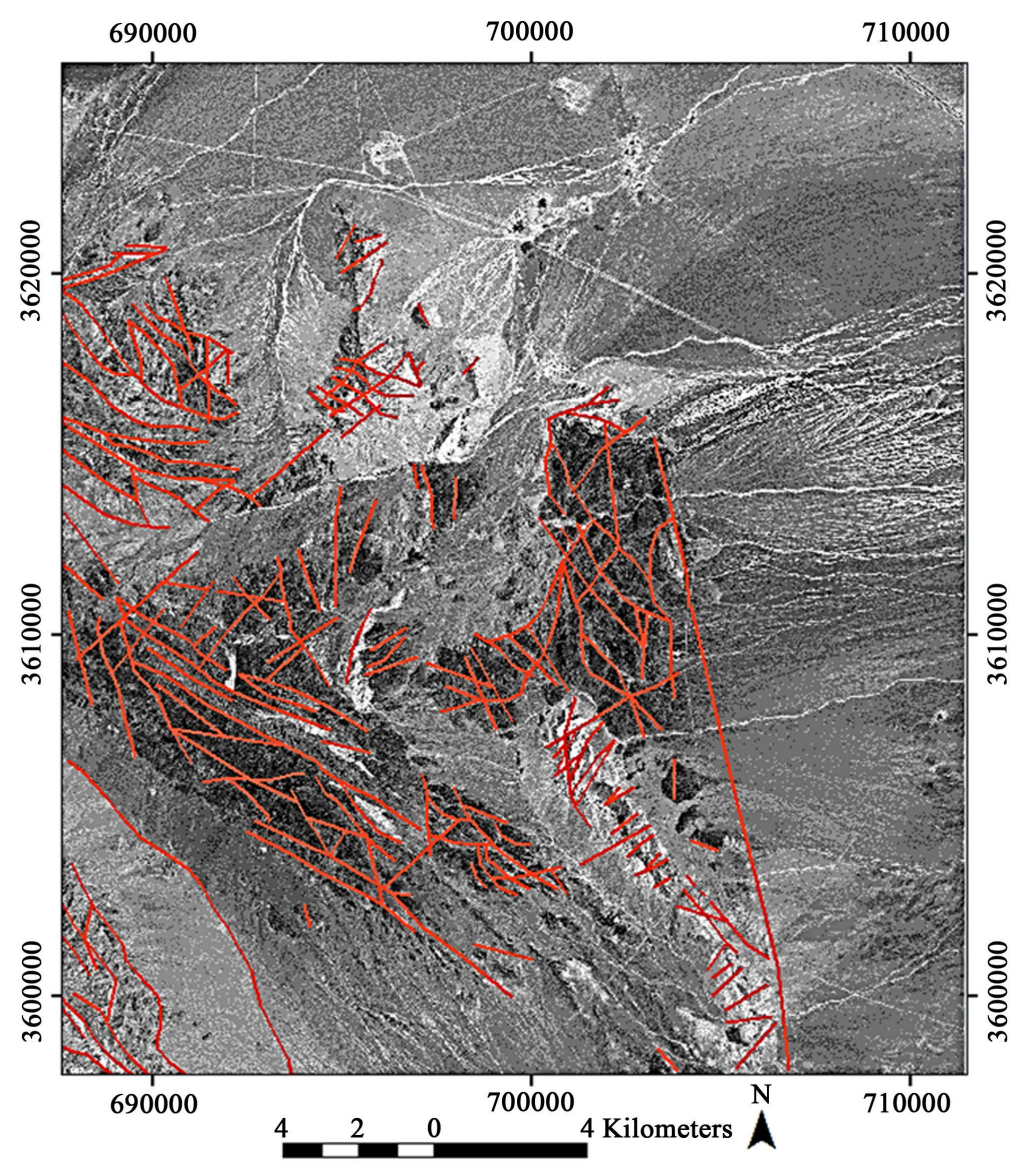

Figure 5. Lineaments of area detected by performing High Gaussian filter on panchromatic band of IRS data.

$11.5-12.5 \mu \mathrm{m}$ ) were not used in this study. Several color combination of Lands at- 8 were created. Vegetation shows absorption at $0.45-0.68 \mu \mathrm{m}$ and high reflectance in the near infrared from 0.7 to $1.2 \mu \mathrm{m}$ and hence become more clear in color composite that contain near infrared region that is positioned in band 5 of Lands at-8. Figure 6 shows the RGB color combination (532) image. The vegetated areas appear in light-red. Textural features of different rocks of area are diagnosed clearly. The vegetated areas were very rare. Iron minerals and vegetation have similar reflectance. Iron oxide minerals have spectral absorption features in the visible to middle infrared from 0.4 to $1.1 \mu \mathrm{m}$ of the electromagnetic spectrum. Vegetation shows absorption features from 0.45 to $0.68, \mu \mathrm{m}$ and high reflectance in near infrared. Iron oxide minerals have high reflectance in the range of $0.63-0.6 \mu \mathrm{m}$, while the range of $0.76-0.90 \mu \mathrm{m}$ covers higher range of the vegetation red edge reflectance feature in near infrared. One of the gole of this study is to detect pixels that contain iron oxide. Hence for more accuracy in assessment iron oxide pixels from vegetation pixels, the normalized difference vegetation index (NDVI) ${ }^{8}$ was applied to determine vegetated areas and their condition and then were already eliminated through masking operation. NDVI

${ }^{8}$ Normalized difference vegetation index. 

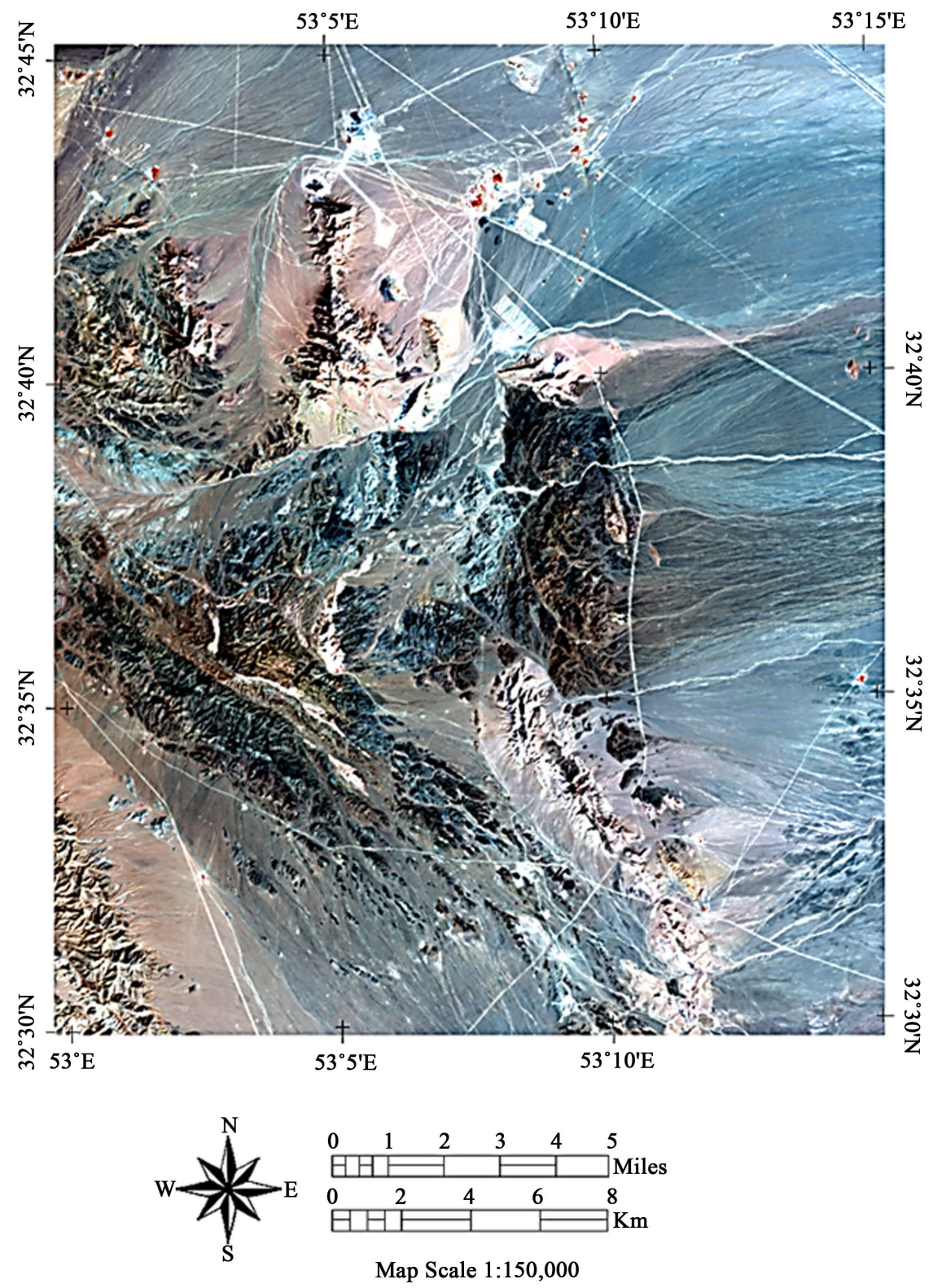

Figure 6. RGB color combination image of bans 5, 3 and 2 .

is a numerical indicator that use the visible and near-infrared bands of the electromagnetic spectrum defined as (NIR - red)/(NIR + red), where NIR stand for the spectral reflectance measurement in near infrared, corresponds to Lands at- 8 band 5 , and red corresponds to Lands at- 8 band 4 .

Hydrothermally altered rocks are identified by iron oxide, clay, carbonate, and sulfate minerals, that have diagnostic absorption signatures. Electronic processes produce absorption features in the visible and near infrared radiation (0.4 to 1.1 $\mu \mathrm{m})$ due to the presence of transition elements such as $\mathrm{Fe}^{2+}, \mathrm{Fe}^{3+}$ and often changed by $\mathrm{Mn}, \mathrm{Cr}$, and $\mathrm{Ni}$ in the crystal structure of the minerals. Supergne alteration processes, interaction with air and surface water, over porphyry copper bodies generate Fe-rich crust with abroad iron oxide/hydroxide minerals (yello- 
wish to reddish color altered rocks), that are collectively termed gossan [5] [9]. Two band ratios were designated on the basis of the laboratory spectra of alteration minerals for mapping iron oxide and gossan. Iron oxide minerals have total reflectivity from $0.5-0.6$ microns and high absorption between 0.45 and 0.52 $\mu \mathrm{m}$ which were mapped with band ratio of $3 / 2$. Related to previous study gossan was detected by using $4 / 2$ band ratio of aster data which the equivalent of it for Lands at 8/oli is 6/3 and used for mapping gossan of area Figure 7 shows the result of band ratio for mapping iron oxide and gossan.

MTTCIMF and OSP algorithm detect Argillic, Phyllic, Propylitic alteration based on key minerals spectrum. Two algorithms were performed to identify alteration zone by considering the reference spectral acquired from standard spectrum data base of USGS. The output of MTTCIMF is set of images that give TCIMF and infeasibility scores with target images of each minerals and the output of OSP algorithm is target images and OSP images of selected minerals for each alteration. In this research alteration mineral assemblages are demonstrated with different colors, narrow argillic areas as blue color for kaolinite and yellow color as alunite, broad phyllic as green color for muscovite. propylitic zone as cyne color for epidote, red color for chlorite and pink color for calcite that has the most expanse in this area. Figure 8 shows alteration detected by MTTCIMF algorithm and Figure 9 Shows alteration detected by OSP algorithm. Results show that porpylitic alteration has the most expanse than other alteration. Argillic and phyllic alteration manifested just by a few pixels. Both OSP and MTTCIMF algorithm identified alteration but in MTTCIMF image it is more clear.

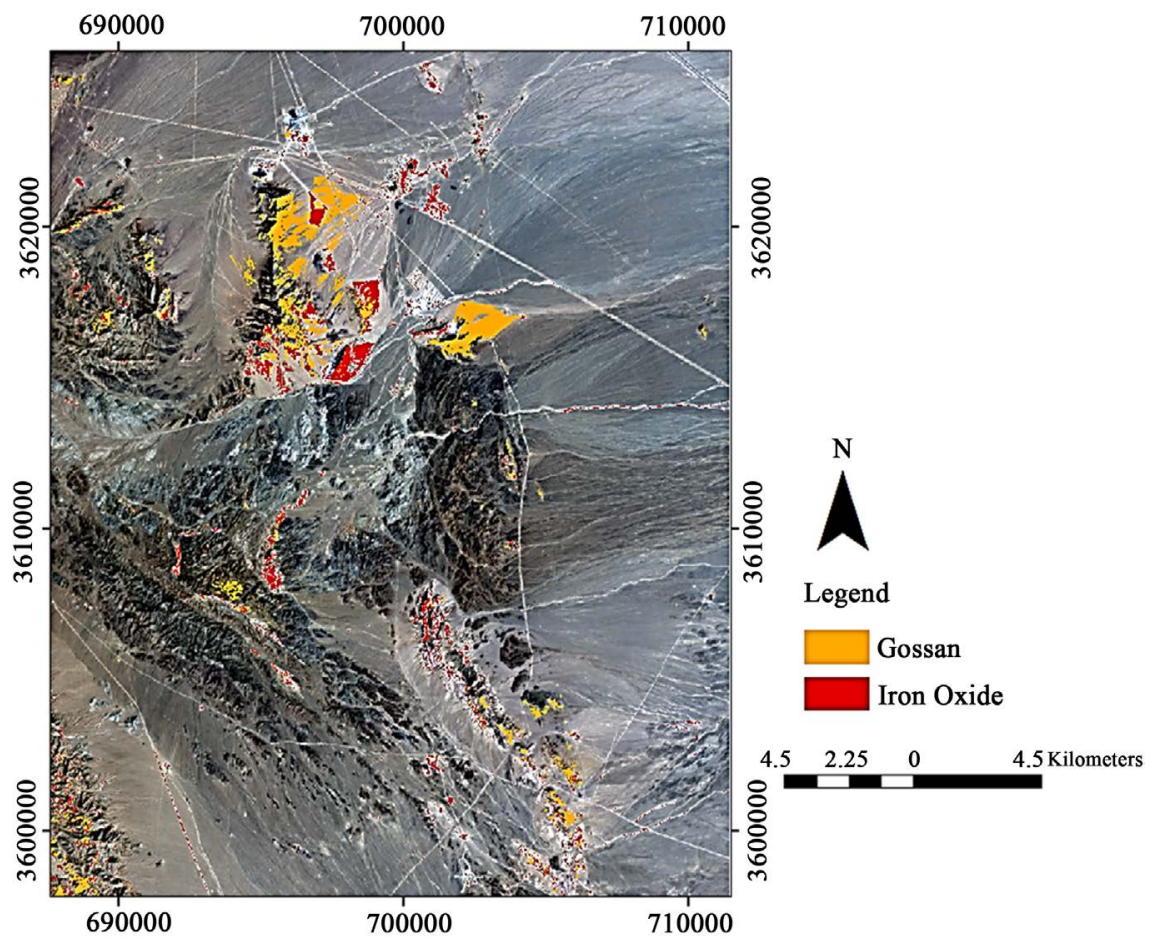

Figure 7. Band ratio of $3 / 2$ for Iron oxide and 6/3 for Gossan of area. 


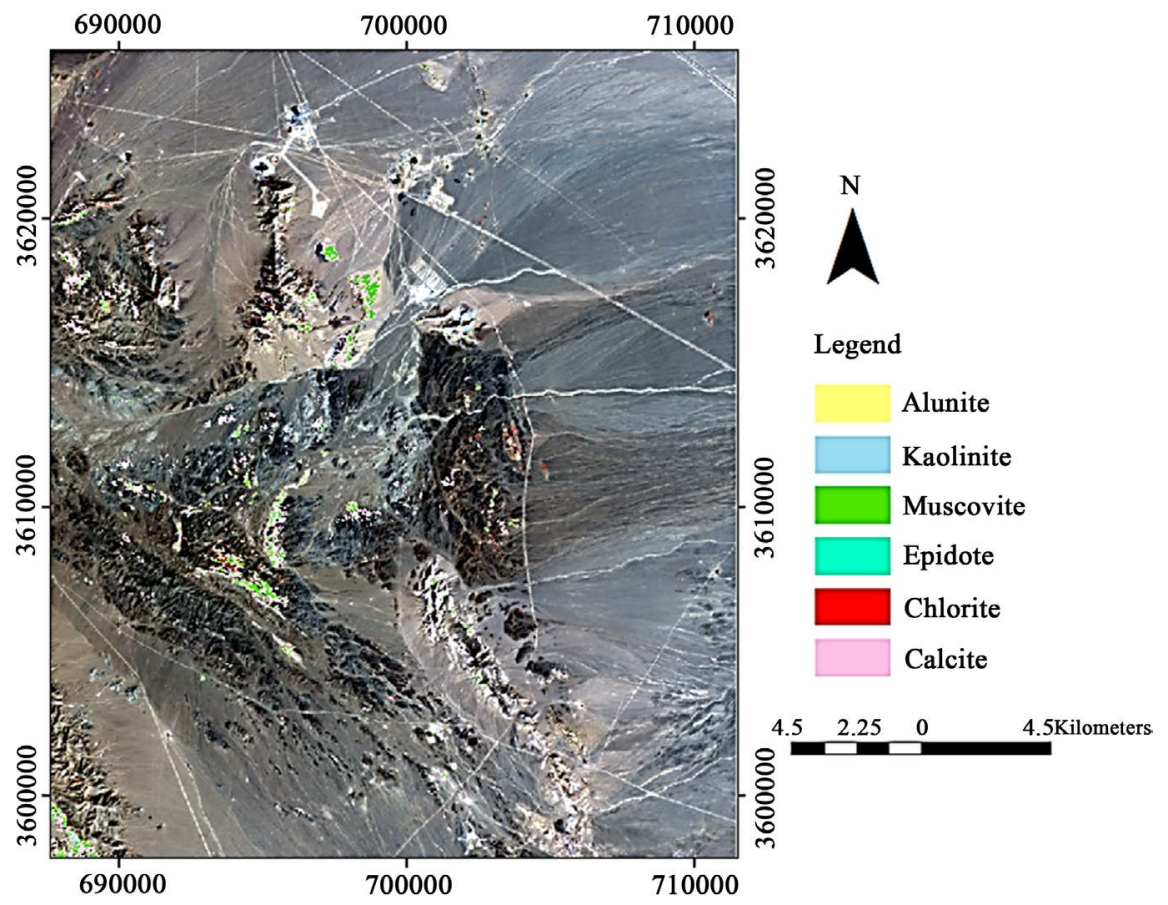

Figure 8. Alteration detected by MTTCIMF technique.

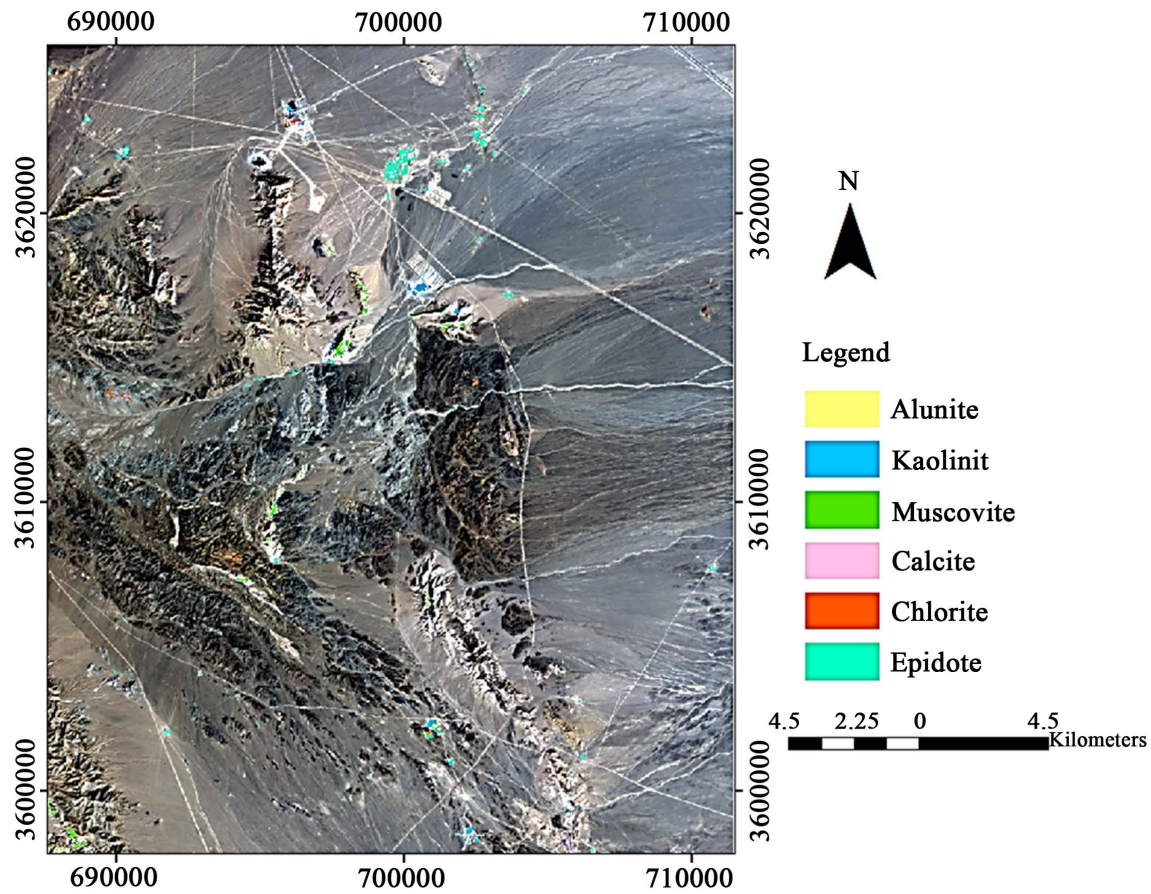

Figure 9. Alteration detected by OSP technique.

\section{Comparison with Ground Truth and Fuzzy Model}

The results of all image processing of band ratio and target detection were perused and six points were selected as the best location for investigation porphyry copper deposit. Figure 10 shows 6 points that were selected. In each point all the alteration were appeared. The validity of the results has been verified through 


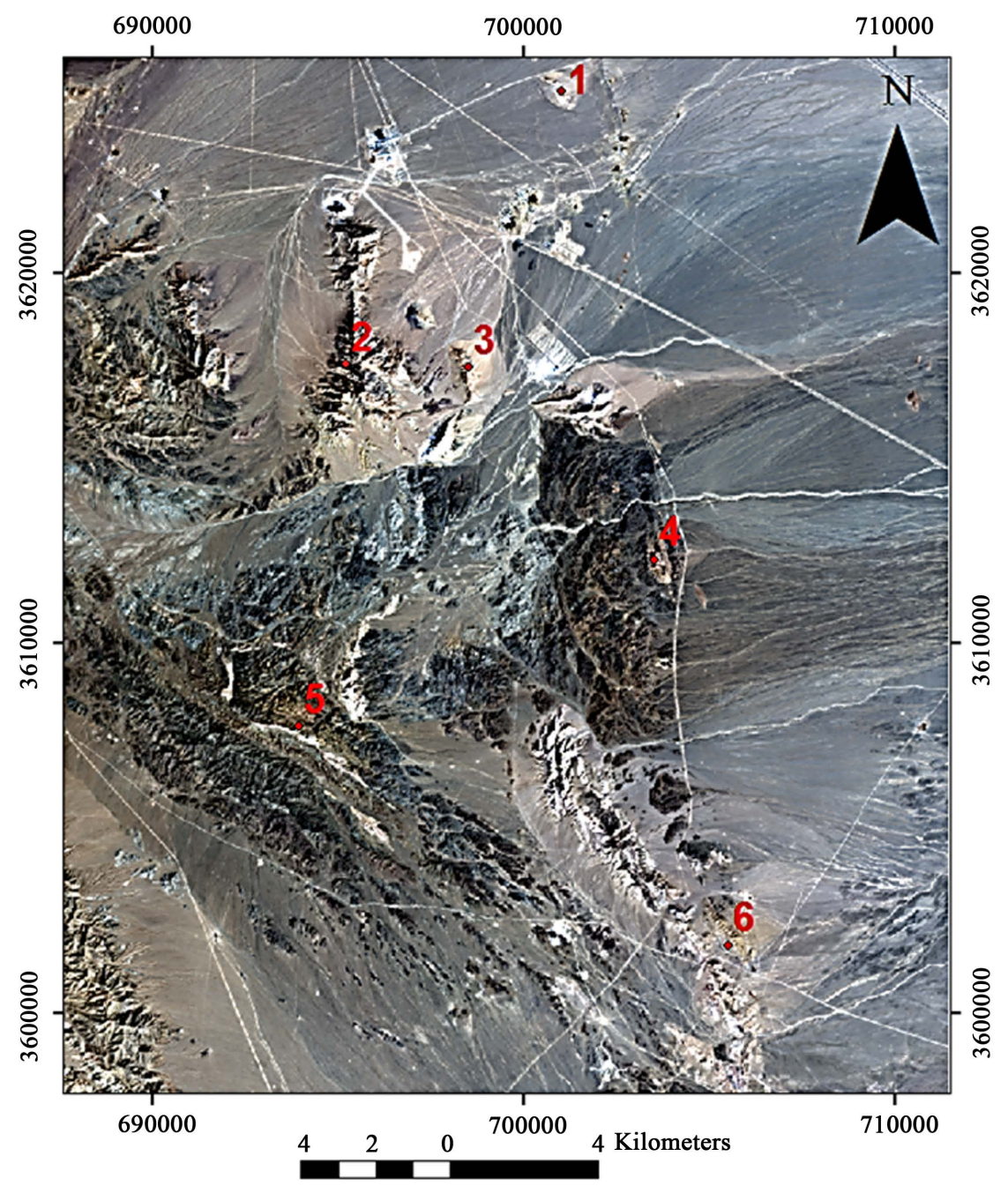

Figure 10. Locations of six points as the best places for investigation.

comparison between image processing results and fieldwork. The latitude and longitude of six points were obtained and the equivalent of them on the ground by GPS survey were found. Rock sampling have been done to obtain comprehensive information of the study area. Figure 11 shows the fieldwork result.

The relationship between lineaments of area and mineralization was evaluated by fuzzy logical model. This method is a partly knowledge-driven and partly data-driven approach [36]. Fuzzy logic can be used with data from any measurement scale and the weighting of evidences. Each of points matched with fieldwork in terms of alteration base on image processing weighted and classified. Point 3 has the most alteration and economic potential for copper investigation. Lineaments of area in terms of distance of six points were selected as the best points for porphyry copper mineralization classified and weighted. Table 1 shows classification. Fuzzy logic model implemented on data in Arc GIS software. Result of fuzzy logic in Figure 12 shows that places with dark blue have the most alteration and mineralization while white places have no alteration with zero possibility for mineralization. 

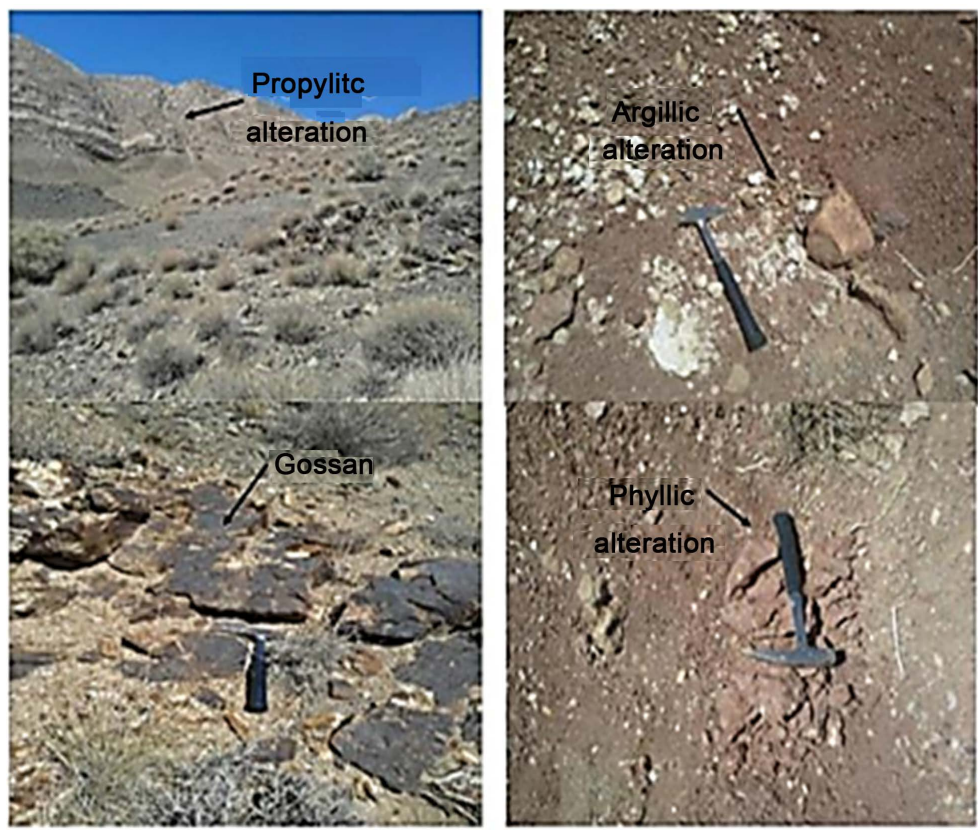

Figure 11. Field photographs of the study area.

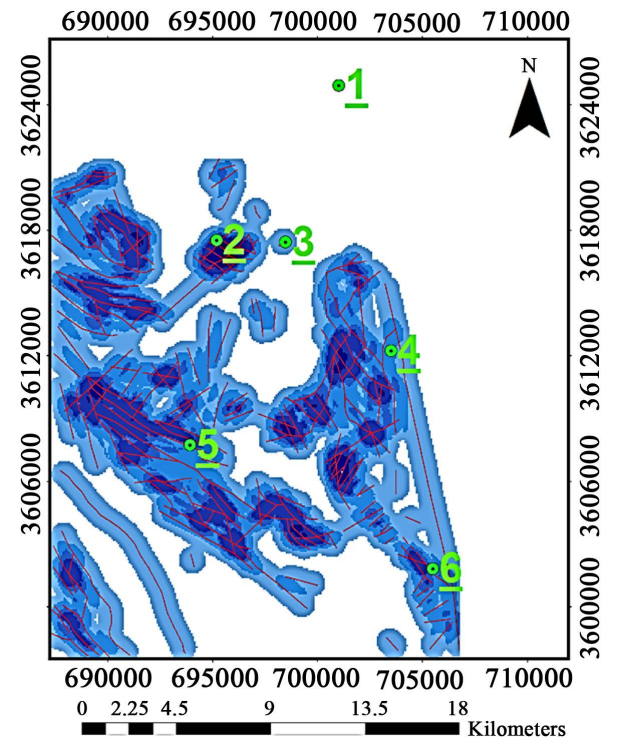

Figure 12. Result of fuzzy model base on relationship of lineaments and alteration.

Table 1. Weighting table modified for fuzzy logic model.

\begin{tabular}{ccc}
\hline Distance of lineaments & Weighting & Selected mineralization points \\
\hline $0-100$ & 3 & 6 \\
$100-200$ & 5 & 4 \\
$200-300$ & 2 & 3 \\
$300-400$ & 6 & 2 \\
$400-500$ & 4 & 6 \\
$500-600$ & 11 & \\
\hline
\end{tabular}




\section{Conclusion}

This study is the first use of remote sensing techniques in exploring minerals in this area. In this research applicability of Lands at-8OLI data for obtaining information on hydrothermal alteration associated with porphyry copper deposits iron oxide and gossan evaluated. Band ratio and target detection carried out for detailed hydrothermal alteration mapping, resulting in the identification of copper mineralization. Analysis of Lands at8 OLI level $1 \mathrm{~T}$ data performed after applying atmospheric correction using Internal Average Relative Reflection (IARR) method .Results of band ratio indicated the iron oxide and gossan of area can be utilized as a useful tool for mapping porphyry copper deposits. The result of MTTCIMF and OSP showed their capability in distinguishing of the argillic and phyllic and propylitic mineral assemblages based on their spectral properties. Lineaments of area were detected base on High Gussion filtering to make clear the relationship of them with mineralization of area. Results are proven to be effective with results of field work and Fuzzy logic. The results were validated using fuzzy logic and comparison between the image-based results and field surveying. To do this, we randomly selected six points over the study area for the field surveying process. In all six points we observed the correlation between Iron and Goassan and the existing faults of the area. This investigation shows that the integration of the image processing techniques and Lands at 8 data have great ability to assist economic geologist for initial stages of mineral exploration, and can be extrapolated to intact area for exploring high potential copper mineralization zones.

\section{Acknowledgements}

This study was carried out as part of the first author's Master of Science thesis at Isfahan (Khorasgan) Branch, Islamic Azad University, Isfahan, Iran.

\section{References}

[1] Sabins, F.F. (1999) Remote Sensing for Mineral Exploration. Ore Geology Reviews, 14, 157-183. https://doi.org/10.1016/S0169-1368(99)00007-4

[2] Mars, J.C. and Rowan, L.C. (2006) Regional Mapping of Phyllic- and Argillic-Altered Rock in the Zagros Magmatic Arc, Iran, Using Advanced Spaceborne Thermal Emission and Reflection Radiometer (ASTER) Data and Logical Operator Algorithms. Geosphere, 2, 161-186. https://doi.org/10.1130/GES00044.1

[3] Zhang, X., Pazner, M. and Duke, N. (2007) Lithologic and Mineral Information Extraction for Gold Exploration Using ASTER Data in the South Chocolate Mountains (California). ISPRS Journal of Photogrammetry and Remote Sensing, 62, 271-282. https://doi.org/10.1016/j.isprsjprs.2007.04.004

[4] Gabr, S., Ghulam, A. and Kusky, T. (2010) Detecting Areas of High-Potential Gold Mineralization Using ASTER Data. Ore Geology Reviews, 38, 59-69.

[5] Hunt, G.R. and Ashley, P. (1979) Spectra of Altered Rocks in the Visible and Near Infrared. Economic Geology, 74, 1613-1629. https://doi.org/10.2113/gsecongeo.74.7.1613 
[6] Ferrier, G. and Wadeg, G. (1996) Application of Imaging Spectrometry Data to Mapping Alteration Zones Associated with Gold Mineralization in Southern Spain. International Journal of Remote Sensing, 17, 331-335.

[7] Ferrier, G., White, K., Griffiths, G., Bryant, R. and Stefouli, M. (2002) The Mapping of Hydrothermal Alteration Zones on the Island of Lesvos, Green, Using an Integrated Remote Sensing Data Set. International Journal of Remote Sensing, 23, 341-356. https://doi.org/10.1080/01431160010003857

[8] Abdelsalam, M. and Stern, R. (2000) Mapping Gossans in Arid Regions with Lands at TM and SIR-C Images, the Beddaho Alteration Zone in Northen Erittea. Journal of African Earth Sciences, 30, 903-916. https://doi.org/10.1016/S0899-5362(00)00059-2

[9] Hunt, G.R. (1977) Spectral Signatures of Particulate Minerals in the Visible and near Infrared. Geophysics, 42, 501-513. https://doi.org/10.1190/1.1440721

[10] Crowley, J.K. and Vergo, N. (1988) Near-Infrared Reflectance Spectra of Mixtures of Kaolin Group Minerals: Use in Clay Mineral Studies. Clays Clay Minerals, 36, 310-316. https://doi.org/10.1346/CCMN.1988.0360404

[11] Clark, R.N., King, T.V.V., Klejwa, M. and Swayze, G.A. (1990) High Spectral Resolution Reflectance Spectroscopy of Minerals. Journal of Geophysical Research, 95, 12653-12680. https://doi.org/10.1029/JB095iB08p12653

[12] Dilles, J.H. and Einaudi, M.T. (1992) Wall-Rock Alteration and Hydrothermal Flow Paths about the Ann-Mason Porphyry Copper Deposit, Nevada-a 6-km Vertical Reconstruction. Economic Geology, 87, 1963-2001.

https://doi.org/10.2113/gsecongeo.87.8.1963

[13] Spatz, D.M., Wilson, R.T., Pierce, F.W. and Bolm, J.G. (1995) Remote Sensing Characteristics of Porphyry Copper Systems, Western America Cordillera. Arizona Geological Society Digest, 20, 94-108

[14] Dalton, J.B., Bove, D.J., Mladinich, C.S. and Rockwell, B.W. (2004) Identification of Spectrally Similar Materials Using the USGS Tetracorder Algorithm: The Calcite-Epidot-Chlorite Problem. Remote Sensing of Environment, 89, 455-466. https://doi.org/10.1016/j.rse.2003.11.011

[15] Rowan, L.C., Schmidt, R.G. and Mars, J.C. (2006) Distribution of Hydrothermally Altered Rocks in the RekoDiq, Pakistan Mineralized Area Based on Spectral Analysis of ASTER Data. Remote Sensing of Environment, 104, 74-87. https://doi.org/10.1016/j.rse.2006.05.014

[16] Hovis, W.A. (1965) Infrared Reflectivity of Iron Oxide Minerals. Icarus, 4, 425-430. https://doi.org/10.1016/0019-1035(65)90048-5

[17] Ghorbani, M. (2013) The Economic Geology of Iran: Mineral Deposits and Natural Resource. Springer, Netherlands.

[18] Hossein, S., Mokhtari, A. and Tehrani, E.N. (2014) Effects of Land Use/Land Cover Changes on Surface Runoff (A Case Study in Siahroud Watershed, Iran). Elixir Remote Sensing, 74, 26867-26870.

[19] Mohammadian, M., Arfania, R. and Sahour, H. (2017) Evaluation of SEBS Algorithm for Estimation of Daily Evapotranspiration Using Lands at-8 Dataset in a Semi-Arid Region of Central Iran. Open Journal of Geology, 7, 335-347.

[20] Hossein, S., Mokhtari, A. and Ghahfarokhi, S.S. (2016) Rainfall-Runoff Modeling Using Remotely Sensed Data and Hydrologic Modeling System. Ecology, Environment and Conservation Paper, 22, 1725-1745.

[21] Inzana, J., Kusky, T., Higgs, G. and Trucker, R. (2003) Supervised Classifications of 
Lands at TM Band Ratio Images and Lands at TM Band Ratio Image with Radar for Geological Interpretation of Central Madagscar. Journal of African Earth Sciences, 37, 59-72. https://doi.org/10.1016/S0899-5362(03)00071-X

[22] Ali, A. and Pour, A.B. (2014) Lithological Mapping and Hydrothermal Alteration Using Landsat 8 Data: A Case Study in Ariab Mining District, Red Sea Hills Sudan. International Journal of Sciences. Basic and Applied Research, 3, 199-208.

[23] Kumar, C.H., Shetty, A., Raval, S., Champatiray, P.K. and Sharma, R. (2014) Sub-Pixel Mineral Mapping Using EO-1 Hyperrion Hyperspectral Data. The International Archives of the Photogrammetry, Remote Sensing and Spatial Information Sciences, XL-8, 455-461.

[24] Rockwell, B.W. and Hofstra, A.H. (2008) Identification of Quartz and Carbonate Minerals across Northern Nevada Using ASTER Thermal Inferared Emissivity Data-Implications for Geologic Mapping and Mineral Resource Investigations in Well-Studied and Frontier Area. Geosphere, 4, 218-246.

[25] Gad, S. and Kusky, T. (2007) ASTER Spectral Ratioing for Lithological Mapping in the Arabian-Nubian Shield, the Neoproterozoic Wadi Kid Area, Sinai, Egypt. Gondwana Research, 11, 326-335. https://doi.org/10.1016/j.gr.2006.02.010

[26] Kruse, F.A., Perry, S.L. and Caballero, A. (2006) District Level Mineral Survey Using Airborne Hyperspectral Data, LosMenucos, Argentina. Annals of Geophysics, 49, 83-92.

[27] Magendran, T. and Sanjeevi, S. (2013) Hyperion Image Analysis in the Part of Noamundi, Eastern India. International Journal of Applied Earth Observation and Geoinformation, 26, 413-426. https://doi.org/10.1016/j.jag.2013.09.004

[28] Molan, Y.E., Refali, D., Tarashti, A.H. (2014) Mineral Mapping in the Maherabad Area, Eastern Iran, Using HyMap Remote Sensing Data. International Journal of Applied Earth Observation and Geoinformation, 27, 117-127. https://doi.org/10.1016/j.jag.2013.09.014

[29] Zhang, X. and Li, P. (2014) Lithological Mapping from Hyperspectral Data by Improved Use of Spectral Angle Mapper. International Journal of Applied Earth $O b$ servation and Geoinformation, 31, 95-109. https://doi.org/10.1016/j.jag.2014.03.007

[30] Rahimzadegan, M., Sadeghi, B., Masoumi, M. and Ghalehjoghi, S.T. (2014) Application of Target Detection Algorithms to Identification of Iron Oxides Using Aster images: A Case Study in the North of Semnan Province, Iran. Arabian Journal of Geosciences, 8, 7321-7331. https://doi.org/10.1007/s12517-014-1757-4

[31] Jin, X., Paswaters, S. and Cline, H. (2009) A Comparative Study of Target Detection Algorithms for Hyperspectral Imagery. Proceedings Algorithm and Technologies for Multispectral, Hyperspectral and Ultraspectral Imagery XV. International Society for Optics and Photonics, XV 73341 W, Orlando, Florida, United States, 27 April 2009. https://doi.org/10.1117/12.818790

[32] Ren, H. and Chang, C. (2000) Target-Constrained Interference-Minimized Approach to Subpixel Target Detection for Hyperspectral Images. Optical Engineering, 39, 3138-3145. https://doi.org/10.1117/1.1327499

[33] Di Tommaso, I.D. and Rubinstein, N. (2007) Hydrothermal Alteration Mapping Using ASTER Data in the Infiernillo Porphyry Deposit, Argentina. Ore Geology Reviews, 32, 275-290. https://doi.org/10.1016/j.oregeorev.2006.05.004

[34] Bassi, H.G.L. (1992) Hypothesis Concerning a Regmagenic Network Controlling Metallogenic and Other Geologic Events in the South American Austral Cone. Geologische Rundschau, 77, 491-511. 
[35] Dogan, H.M. (2008) Application of Remote Sensing and Geographic Information System to Assess Ferrous Minerals and Iron Oxide of Tokat Province in Turkey. International Journal of Remote Sensing, 29, 221-233.

https://doi.org/10.1080/01431160701269010

[36] Derakhshani, R. and Mehrabi, A. (2014) Geologically-Contrained Fuzzy Mapping of Porphyry Mineralization Potential, Meiduk District, Iran. Trends in Applied Sciences Research, 4, 229-240. https://doi.org/10.3923/tasr.2009.229.240 